\section{Mentoring Structures and the Types of Support Provided to Early-Year Undergraduate Researchers}

\author{
Gaye D. Ceyhan ${ }^{\ddagger * *}$ and John W. Tillotson ${ }^{\dagger}$ \\ 'Department of Science Teaching, Syracuse University, Syracuse, NY 13244; 'Department of \\ Mathematics and Science Education, Bogazici University, Istanbul, Turkey 34342
}

\begin{abstract}
Research has shown that mentorship provided to undergraduate researchers affects the extent of research outcomes. Although a large body of literature focuses on the faculty-undergraduate dyad mentorship structure, little is known about mentoring triads (i.e., interaction among undergraduate students, faculty, and graduate students or postdoctoral associates) or the support provided to early-year undergraduate researchers. Mentors provide various types of support (e.g., intellectual, personal, emotional, and professional support) to undergraduate researchers to increase their engagement in a discipline. This qualitative exploratory study aims to investigate undergraduate researchers' perspectives on mentoring structures and the support provided to them in their first and sophomore years. The majority of participants described the mentorship they received as having a triad structure, indicating interaction with both faculty and postgraduates. Participants also reported receiving different types of support from faculty and postgraduates depending on their mentoring structures and the amount of research experience they gained. Given the potential benefits to undergraduate researchers, undergraduate research programs should be designed to provide clear roles, responsibilities, and expectations to maximize the support provided to undergraduate students.
\end{abstract}

\section{INTRODUCTION}

Mentoring is a fundamental component of the undergraduate research (UR) experience (Dolan and Johnson, 2009, 2010; Robnett et al., 2018) because "mentors provide guidance, information, and support that help undergraduates become integrated into their disciplines" (Aikens et al., 2017, p. 1). The UR literature notes that mentorship provided to undergraduate researchers affects the extent of personal and professional benefits attributed to engaging with research (Gregerman et al., 1998; Hunter et al., 2007; Thiry et al., 2011; Fuentes et al., 2014). Specifically, according to Lave and Wenger's (1991) community of practice perspective, mentoring has been found to be a predictor of students' stronger science identity and commitment to science, technology, engineering, and mathematics (STEM) fields (Chemers et al., 2011). However, faculty mentors have limited time and resources to provide effective mentoring to undergraduate researchers. To increase the availability of UR opportunities for undergraduate students, undergraduate researchers in most research universities are not directly mentored by faculty (Dolan and Johnson, 2010; Thiry and Laursen, 2011). In these cases, graduate students or postdoctoral associates (together referred to as "postgraduates") take on or share the mentorship role for undergraduate students in the UR experience, which creates a mentoring triad (Aikens et al., 2016; Bradley et al., 2017).

All three members of the mentoring triad do not always directly interact with one another regarding the undergraduate's research experience (Joshi et al., 2019). Aikens et al. (2016) listed different mentoring structures in UR, such as undergraduate
Derek Braun, Monitoring Editor

Submitted Sep 18, 2019; Revised Apr 30, 2020; Accepted May 5, 2020

CBE Life Sci Educ September 1, 2020 19:ar26 DOI:10.1187/cbe.19-09-0183

*Address correspondence to: Gaye D. Ceyhan (gaye.ceyhan@boun.edu.tr)

ORCID ID: https://orcid.org/0000-0003-13123547.

(c) 2020 G. D. Ceyhan and J. W. Tillotson. CBE-Life Sciences Education (C) 2020 The American Society for Cell Biology. This article is distributed by The American Society for Cell Biology under license from the author(s). It is available to the public under an Attribution-Noncommercial-Share Alike 3.0 Unported Creative Commons License (http://creativecommons.org/ licenses/by-nc-sa/3.0).

"ASCB®" and "The American Society for Cell Biology ${ }^{\circledR}$ " are registered trademarks of The American Society for Cell Biology. 


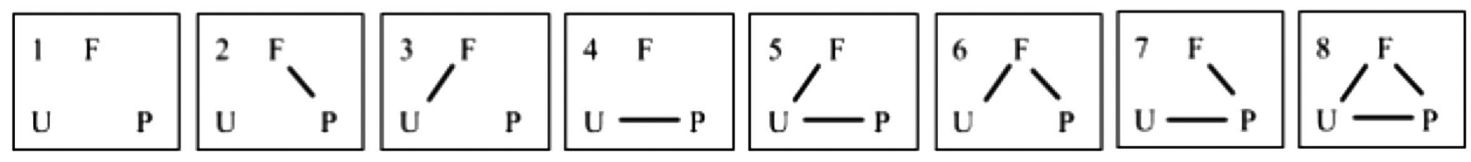

FIGURE 1. UR mentoring triad structures. U, undergraduate researcher; F, faculty; and P, postgraduate. Lines represent a direct interaction (i.e., link) between members of the undergraduate student's research experience team (Aikens et al., 2016, p. 3).

researchers being directly mentored only by faculty, only by postgraduates, or by both postgraduates and faculty or being directly mentored by postgraduates and indirectly mentored by faculty. In Figure 1, a line represents direct interaction among the members of the triad. For instance, a closed triad (triad 8) is represented with a line between each pair of members and includes direct interaction among undergraduates, postgraduates, and faculty mentors regarding the undergraduate's research experience. These direct and indirect mentorship designs that include faculty, postgraduates, and undergraduate students are referred to as "triad mentoring structures" or "mentoring networks" (Aikens et al., 2016).

Mentoring triads can take different forms depending on the institution, program structure, or culture of the research laboratory (Dolan and Johnson, 2010; Aikens et al., 2016). A large body of literature focuses on the faculty-undergraduate dyad mentorship structure (Thiry and Laursen, 2011; Schwartz, 2012; Fuentes et al., 2014; Robnett et al., 2018). However, little is known about the roles and responsibilities of different actors in the mentoring triad structure and what kind of support is provided to undergraduate researchers during this experience (Joshi et al., 2019). Moreover, the types of support provided to early-year undergraduate researchers are understudied (Thiry and Laursen, 2011; Robnett et al., 2018; Joshi et al., 2019). The current study aims to better understand mentoring provided by different actors of the mentoring triad structure-faculty and postgraduates, who are members of a community of practiceas well as the types of support provided to undergraduate researchers in their first and sophomore years. Specifically, this study aims to answer the following questions:

1. What types of mentoring structures do early-year undergraduate researchers experience?

2. What types of support, if any, do early-year undergraduate researchers experience?

\section{UNDERGRADUATE RESEARCH AS A COMMUNITY OF PRACTICE}

Situated learning theory indicates that, within a community of practice, learning takes place through the actions of groups and participation in the authentic activities of a community (Lave and Wenger, 1991; Wenger, 1998). Learning occurs through a process of enculturation, emphasizing the sociocultural setting and the activities of the people within the setting (Wenger, 1998). In this context, "learning is not an accumulation of information, but a transformation of the individual who is moving toward full membership in the professional community" (Hmelo and Evensen, 2000, p. 4). The experience is more than learning by doing; it is socially situated and embedded in an authentic context. UR provides an opportunity for students to learn in a situated context that involves social and cultural interaction to promote their intellectual development through participation in either the authentic or simulated activities of a community of practice.

"Newcomers" enter a community of practice as peripheral members who have limited responsibility for the project or research and its procedures. Lave and Wenger (1991) described the limited role of newcomers as follows: "A newcomer's tasks are short and simple, the costs of errors are small, the apprentice has little responsibility for the activity as a whole" (p. 110). Through authentic engagement in the community and with the support and guidance of senior partners, newcomers increase their roles and responsibilities within the community (Bowman and Holmes, 2018). Mentors in UR assume the role of the senior partner by helping undergraduate researchers increase the benefits of their participation and enhance their authenticity in learning. Increasing our understanding of mentoring may help educators and researchers identify the elements that can be modified to guide newcomers to move from peripheral participation to a more essential role in the community of practice.

\section{MENTORING AND SUPPORT IN UNDERGRADUATE RESEARCH}

Student-faculty interactions can occur in multiple forms in curricular and cocurricular contexts that enable the interaction of faculty and students outside the classroom setting, providing various types of support to undergraduate students (Lopatto, 2010; Thiry and Laursen, 2011; Brackalorenz et al., 2017). Mentoring in UR can be a powerful context for effective student-faculty interaction (Lopatto, 2010; Amaya et al., 2018). Students who participate in UR report that the research experience creates an environment for them to engage in substantial relationships with faculty, leading to greater motivation, engagement, academic performance, and achievement (Kim and Sax, 2009; Brackalorenz et al., 2017; Garvey et al., 2018; Schreiner and Tobolowsky, 2018). The term "mentoring" has been defined in the literature within the context of research as follows:

Mentoring is a personal and reciprocal relationship in which a more experienced (usually older) faculty member acts as a guide, role model, teacher, and sponsor of a less experienced (usually younger) faculty member or student. A mentor provides the mentee with knowledge, advice, counsel, challenge, and support in the mentee's pursuit of becoming a full member of a particular profession. (Johnson, 2015, p. 23)

The literature is clear about the importance of mentoring and faculty mentoring as crucial components of UR, but such mentoring is only one piece of the puzzle. In the UR community, it is a common practice for students to have multiple mentors, especially in STEM fields (Bradley et al., 2017; Linn et al., 2015; Pollock et al., 2017). Pollock et al. (2017) stated that 
"multi-mentoring can be more effective than dyadic mentoring because of the collaborative interactions among diverse, skilled people" (p. 4). Although there may be other senior members in the laboratory environment, such as postgraduates, who play a role in the research experience of undergraduate researchers, their contribution to the undergraduate researchers' experience is understudied in the literature (Dolan and Johnson, 2010; Aikens et al. 2016; Morales et al., 2018). The substantive roles and responsibilities fulfilled by different members of the research laboratory and the types of support these members provide are not clearly defined (Limeri et al., 2019).

As described in the definition, mentors provide various types of support to undergraduate researchers to increase their engagement in a discipline (e.g., intellectual, personal, emotional, and professional support) (Dolan and Johnson, 2009, 2010; Thiry and Laursen, 2011; Robnett et al., 2018). In their study with 66 undergraduate-mentor dyads, Robnett et al. (2018) reported that task-focused mentoring that provided informational support had the highest impact in explaining the students' science identity. Their findings, in line with the literature, indicate the importance of skill-based support from mentors (Chemers et al., 2011; Thiry and Laursen, 2011; Syed et al., 2018). Although some studies have indicated that both informational and socioemotional mentoring are significant dimensions of mentoring (Chemers et al., 2011; Thiry and Laursen, 2011; Robnett et al., 2018), Syed et al. (2018) reported that the two studies they conducted with undergraduate and graduate students to test the mediators of research experience showed informational mentoring, but not socioemotional mentoring, to be a significant predictor of commitment.

Dolan and Johnson (2010) reported that postgraduate mentors may provide technical and informational support to undergraduate researchers. Compared with faculty mentors, postgraduate mentors may develop closer and/or more effective relationships with undergraduate researchers because of their more recent undergraduate experiences (Dolan and Johnson, 2009,2010 ). However, postgraduates can also have a negative impact on undergraduates by imposing high expectations, pressuring undergraduate students to work long hours, and establishing a sense of hierarchy in the research laboratory, which may result in decreased student gains in knowledge and skills (Dolan and Johnson, 2010; Morales et al., 2018).

The abovementioned studies offer valuable information about mentorship and support provided to undergraduate researchers by faculty and postgraduates. However, the current literature predominantly examines support systems provided to junior and senior undergraduate researchers rather than first or sophomore undergraduate researchers. Studies on UR have reported associations between UR participation and several student outcomes, such as higher rates of student-faculty interaction (Garvey et al., 2018; Schreiner and Tobolowsky, 2018), higher perceived science identity (Chemers et al., 2011; Robnett et al., 2015, 2018), stronger persistence and higher grade point average (Rodenbusch et al., 2016), and higher student engagement overall (Kuh, 2008). UR may guide students to "sink their roots in the culture of the discipline" (Merkel, 2003, p. 41) and explore career choices or participate in a graduate degree (Lopatto, 2010). Early engagement in UR may be beneficial and may result in different short-term and long-term outcomes than later research engagement (Bowman and Holmes, 2018;
Hernandez et al., 2013). The present qualitative exploratory study aimed to contribute to the literature by clarifying the possible relationships of mentoring and the type of support provided to undergraduate researchers in their first and sophomore years, as well as to identify the most promising avenues for future studies. To address the research questions, the article includes two sections: the first section describes the mentoring structures, and the second section explains the domains of support provided to the participants.

\section{METHODOLOGY \\ Setting}

This study was conducted at a large, research-intensive private university in the northeastern United States to qualitatively explore the mentorship and types of support provided to undergraduate researchers in their first and sophomore years. The primary setting was the Strategic Undergraduate STEM Talent Acceleration Initiative (SUSTAIN) project, a 3-year longitudinal study funded by the National Science Foundation (NSF) to recruit and retain low-income, high-achieving undergraduate students in STEM majors in the first and second years of their undergraduate study. The project provided academic, social, and professional support interventions, as well as financial support to 28 low-income, academically talented STEM students from diverse backgrounds who were in the first two years of their undergraduate studies in the biology and chemistry departments. As part of the project, this study focused only on the research program provided to the SUSTAIN project participants in their first and sophomore years.

\section{Participants}

The participants of this study were 24 of the original 28 SUSTAIN project participants. Four of the SUSTAIN project participants were removed from the current study, because they did not participate in some or all of the project interventions. Two of the project participants left the university at the end of first year. Another project participant did not participate in the project interventions, including UR; switched to a non-science major at the end of his/her first year; and did not participate in some or all of the data collection. Finally, one of the project participants had health issues and took a leave of absence and did not participate in some or all data collection in his/her sophomore year. The participants of the study were predominantly female ( $72 \%$ female and $28 \%$ male), mostly firstgeneration college students (88\%), and racially/ethnically diverse (13\% Asian, 8\% Black/African American, 8\% Hispanic, $21 \%$ multiracial, and 50\% white).

\section{Procedure}

During the Fall 2017 semester, the project principal investigators (PIs) contacted faculty in the biology and chemistry departments to explain the purpose of the project and the expectations of STEM faculty and to ask if they would like to be research faculty mentors for the SUSTAIN project participants. Faculty who volunteered received $\$ 500$ of summer compensation for each project participant they mentored. At the end of the Fall 2017 semester, the SUSTAIN project participants were asked to rank their top five STEM mentor choices after they reviewed the mentors' research profiles online. The project team shared these 


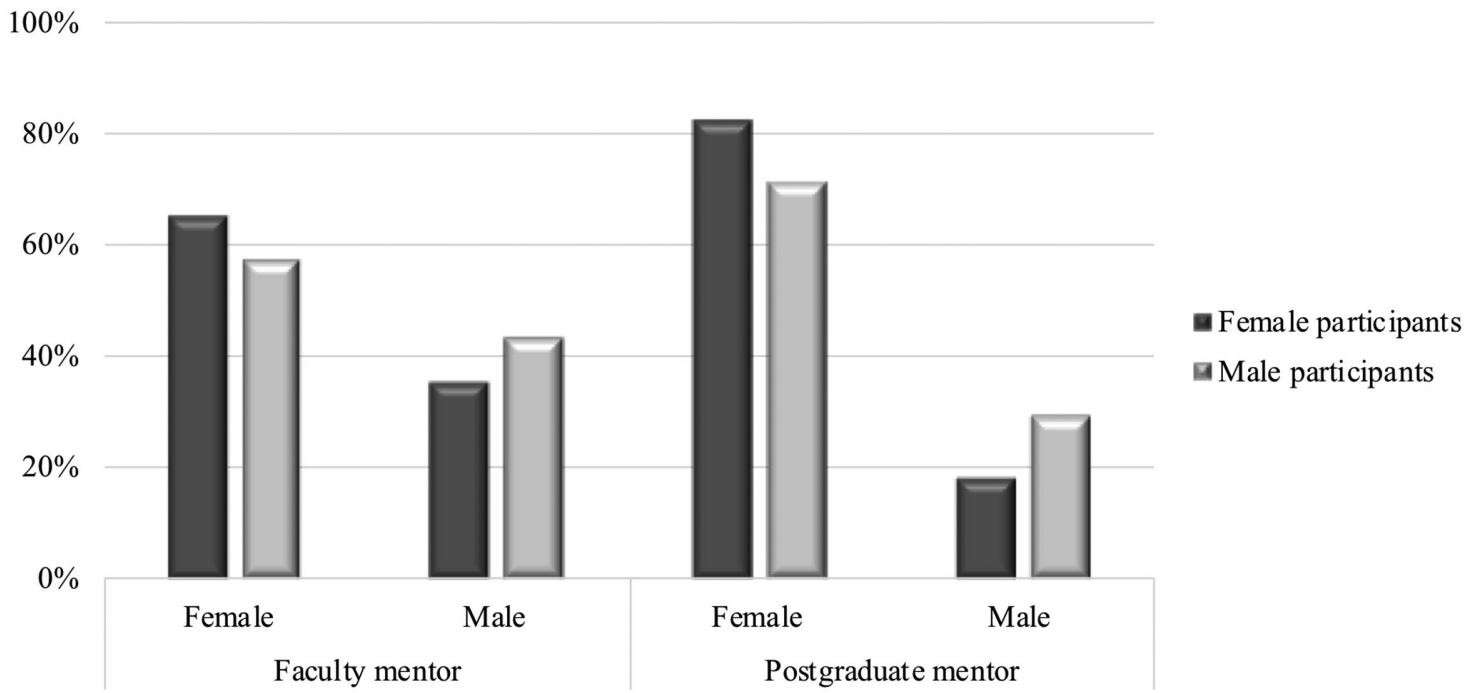

FIGURE 2. Gender distribution of faculty and postgraduate mentors.

tentative matches with the STEM mentors and held an overview meeting for the SUSTAIN project participants and mentors. Faculty mentors set expectations regarding the specific hours the participants would work each week, what they would like the participant(s) to accomplish during the experience, the specific laboratory techniques/procedures they should begin/ continue learning, and the specific laboratory activities/routines they were expected to participate in (e.g., group meetings, colloquia).

Participants in all placements had access to both faculty and postgraduates as possible mentors. Every faculty mentor had postgraduates available to serve as mentors, which was explicitly explained to students. The process of matching faculty mentors with the participants was conducted as described above, while student matches with postgraduate mentors emerged organically during the participants' research experiences. The project team did not control the selection or assignment of postgraduate mentors. As seen in Figure 2, both female and male participants had mostly female faculty mentors and female postgraduate mentors.

The participants spent approximately $3-5$ hours per week throughout the Spring 2018 semester observing and participating in research activities as deemed appropriate by their STEM faculty mentors. During sophomore year, the partici-

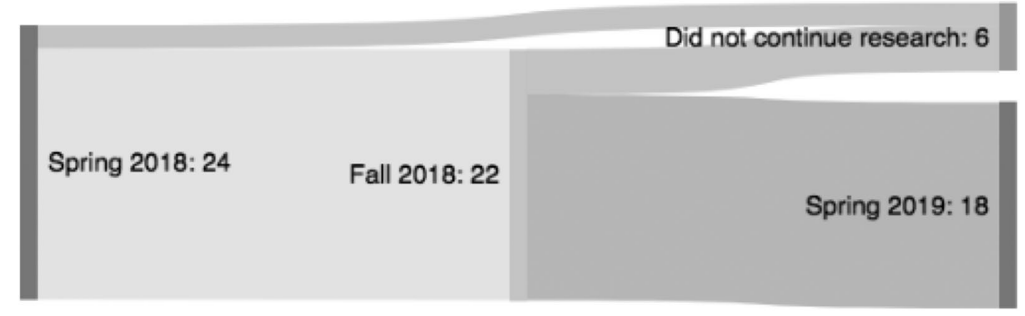

FIGURE 3. River plot showing the number of research experiences occurring in each semester. pants spent approximately 5-10 hours per week in the research laboratory engaging in guided but more independent UR with their STEM faculty mentors using the knowledge and skills acquired during their first-year research experiences. At the end of the Spring 2019 semester, the participants were encouraged to participate in the research poster fair in the biology and chemistry departments, which was an opportunity for them to engage with other STEM students and STEM faculty who would contribute to their socialization within the STEM community.

\section{Amount of Research Experience}

After the matching process, each SUSTAIN project participant started his or her UR experience in a STEM faculty mentor's laboratory in the biology, chemistry, forensic science, neuroscience, or biochemistry programs during the Spring semester of first year. Participants gained different amounts of research experience, because some of them did not continue their research experiences at the end of the first or second semester, while some of them preferred to stay on campus during the summer to continue their research. Two participants did not continue their research at the end of first year; in total, six participants did not continue their research in the Spring semester of sophomore year (see Figure 3).

Regarding their total research experience gained through the project, eight participants had three semesters and one summer, 10 participants had three semesters, four participants had two semesters, and two participants had one semester of research experience. Therefore, the vast majority of the participants gained three semesters or more of research experience. Fourteen female and four male participants gained three semesters or more of research experience. Eleven white, two Asian, both of the Black or African American, one of the Hispanic or Latino, and two multiracial participants gained three semesters or more of research experience. 


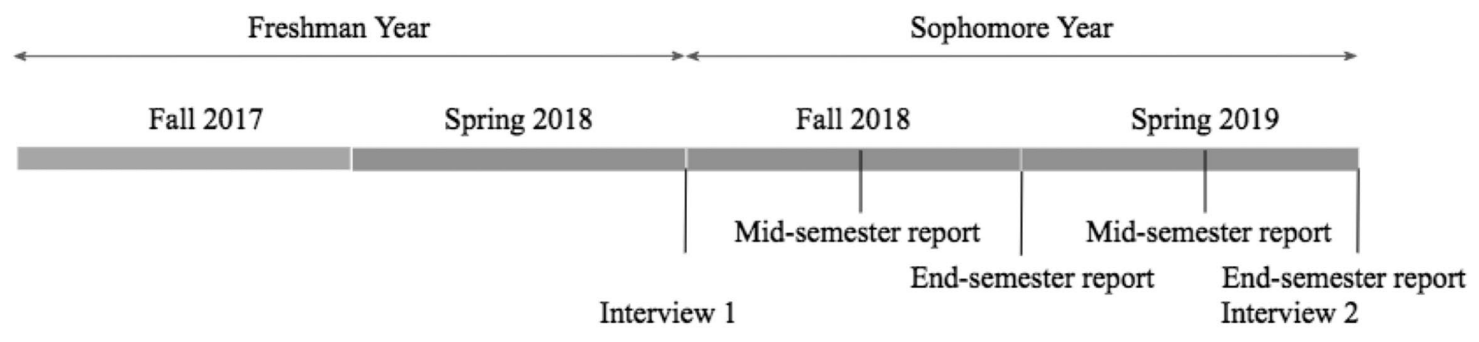

FIGURE 4. Timeline of the data collection.

\section{Research Design and Measures}

This study was designed as an exploratory qualitative inquiry to investigate how undergraduate researchers perceived the support and mentoring provided to them during their UR experiences in their first and sophomore years. As part of the larger project, mentorship data were collected from faculty, postgraduates, and undergraduates, but the present study focused on student perspectives. Data sources for the current study included semistructured interviews with undergraduate researchers and their progress reports to gain an in-depth understanding of the student perspectives about their research experiences. The study instruments were reviewed and approved by the institution's human subject research review board. The researchers also obtained authorization from the review board to use the data sources in this study (IRB no. 19-045). Figure 4 shows the data sources and data-collection times.

Interviews. The interview protocols were developed by the SUSTAIN project team, including two science education experts and three graduate students in science education. A pilot interview was conducted, recorded, and then reviewed by the project team to identify any possible procedural problems and determine the adequacy of the interview protocol. The first set of interviews was conducted in the Spring 2018 semester to assess the participants' first-year research experiences (i.e., the mentoring provided to the participants and their level of satisfaction and engagement with their research experiences). Sample questions from the interviews were "Now that you have spent some time in a research lab, what has your experience been like working with your faculty mentor?," "Would you say your primary mentor is the faculty member, a postdoctoral researcher, a graduate student, or an undergraduate student?," and "To whom in the lab do you direct your questions?" (see Appendix A in the Supplemental Material for the first interview protocol).

The second set of interviews was conducted at the end of the participants' sophomore year in Spring 2019. Some of the questions from the first interview were retained, and some questions were added to understand the participants' sophomore research experiences and determine whether there were differences between their first- and second-year research experiences. Sample questions from the second interviews were "What was your role/responsibility in the lab in your first year/second year? Tell me about your research. Describe some of these things you did" and "How is your second year similar to or different than your first-year research experience?" (see Appendix B in the Supplemental Material for the second interview protocol). The two mentoring structure questions in the interview protocol were adopted from Aikens et al. (2016) and were included to better understand the mentorship provided to the participants. During the interview, the diagram in Figure 1 was presented to the participants and explained ( $F$ indicates the faculty member, $\mathrm{P}$ indicates graduate students or postdoctoral associates, and U indicates the undergraduate student). The question about the domains of support provided to the scholars was adopted from Thiry and Laursen (2011) and was included to explore the different types of support provided to the students during their UR experiences. All interviews were conducted face-to-face, were audio recorded, and had an average duration of 45 minutes. The interviews were then transcribed.

Progress Reports. The goal of having the participants submit progress reports was to obtain continuous information about the participants' expectations and their actual research experiences. Participants submitted midsemester and end-of-semester progress reports (i.e., one midsemester report and one end-of-semester report in both Fall 2018 and Spring 2019). While writing their progress reports, participants were expected to answer questions such as "Before you began your research experience, what did you think the lab experience would be like?," "What did you think participation in the lab would be like?," and "Has your experience differed from your assumptions? If so, are these differences positive, negative or a combination of both?" (see Appendix C in the Supplemental Material for the guidelines for the progress reports).

\section{Data Analyses}

The NVivo Pro 12 qualitative data analysis software program served as the data analysis tool. Each participant was coded with his or her SUSTAIN-ID number and identified as an individual case in the NVivo program. The interviews and progress reports of each participant were uploaded to the program to be organized and analyzed. Before data analysis, the first step was data cleaning and case coding (Feng and Behar-Horenstein, 2019). Each data source was assigned to the corresponding case. For instance, each interview and progress report for the participant with SUSTAIN-ID A was assigned to case A. After the case coding, the case classifications were coded regarding the participants' demographic attributes (gender, race/ethnicity, amount of research experience, and mentoring structure).

Once the case coding and classifications were completed, the patterns in the data that clustered around particular themes, called "domains," were determined (Spradley, 1980). Three domains of the support provided to the participants were identified: intellectual support, personal/emotional support, and 
professional support. These domains represented the patterns in the data and were formulated based on previous studies (Dolan and Johnson, 2010; Thiry and Laursen, 2011; Aikens et al., 2016; Bradley et al., 2017; Amaya et al., 2018; Robnett et al., 2018). During the domain analysis, the coding framework was constructed by reading and rereading the data and searching for key words (i.e., domains), and the domains formed the top-level nodes.

After the domain analysis was complete, a taxonomic analysis was conducted to organize the data under each domain (Leech and Onwuegbuzie, 2011). This process, which is also referred to as the creation of a classification system, facilitated the determination of the concepts related to each domain; this analysis involved the identification of relationships and revealed the subcategories within each domain (Spradley, 1980). These subcategories were formed by reading the data in detail and using the text search function in NVivo. Once the initial domains and the subcategories had been established, various componential analyses were conducted to assess the relevance, similarities, and differences among different groups (i.e., gender, race/ethnicity, amount of research experience, and mentoring).

Componential analyses were conducted by using the matrix coding function in NVivo, which allowed comparisons across and between various demographic categories (i.e., case classification attributes) with the participant responses (Feng and Behar-Horenstein, 2019). Code frequencies were calculated to rank concepts in terms of how often they appeared in the student responses; these code frequencies were used to analyze the data, serving as potential indicators of the value of the concepts.

\section{RESULTS}

This research aimed to explore mentoring structures and the types of support provided to early-year undergraduate researchers. To address the research questions, we present the results in two sections: the first section describes the mentor- ing structures, and the second section explains the domains of support provided to the participants. Regarding the mentoring structures, participants reported receiving closed-triad (triad 8), open-triad (triad 7), faculty-only (triad 6), and postgraduate-only (triad 4) mentorship. Regarding the domains of support, participants indicated receiving intellectual, professional, and personal/emotional support from faculty and postgraduates.

\section{Mentors and Mentoring Structure}

Within the community of practice in UR experience, undergraduate researchers engage in research with the guidance of their mentors. In their second interviews, all participants were presented with Figure 1 and asked about the mentorship provided to them in both their first and sophomore years. Seventeen participants expressed that they received direct mentorship from faculty and postgraduates (i.e., closed-triad mentorship, triad 8). On the other hand, three participants expressed that they received direct mentorship from postgraduates and indirect mentorship from faculty (i.e., open-triad mentorship, triad 7), two participants received faculty-only mentorship (triad 6), and two participants received postgraduate-only mentorship (triad 4; see Table 1). The vast majority of participants who indicated that they received closed-triad (triad 8) mentorship (88\%) gained three semesters or more of research experience, while $43 \%$ of the participants who reported that they received open-triad (triad 7), faculty-only (triad 6) or postgraduate-only (triad 4) mentorship gained three semesters of research experience.

\section{Domains of Support}

Once the case coding and classifications were completed, the deductive and inductive analyses revealed that the participants commented on three domains of support provided to them during their research experience: intellectual, professional, and personal/emotional support. These domains represented the patterns in the data and were formulated based on previous

TABLE 1. Mentoring structures and amount of research experience of participants

\begin{tabular}{|c|c|c|c|c|}
\hline Mentoring structure & $\begin{array}{l}\text { Amount of } \\
\text { experience }\end{array}$ & Gender & Race/ethnicity & $\begin{array}{c}\text { Number of } \\
\text { participants }\end{array}$ \\
\hline \multirow{10}{*}{$\begin{array}{l}\text { Direct mentorship by faculty and postgraduate } \\
\quad \text { (i.e., closed triad, triad 8) }\end{array}$} & \multirow{5}{*}{$\begin{array}{l}\text { Three semesters and } \\
\text { one summer }\end{array}$} & Female & White & 3 \\
\hline & & Female & Multiracial & 2 \\
\hline & & Male & Black or African American & 1 \\
\hline & & Male & White & 1 \\
\hline & & Female & Asian & 1 \\
\hline & \multirow[t]{3}{*}{ Three semesters } & Female & White & 5 \\
\hline & & Male & Asian & 1 \\
\hline & & Male & Hispanic or Latino & 1 \\
\hline & Two semesters & Male & Asian & 1 \\
\hline & One semester & Female & Multiracial & 1 \\
\hline \multirow{2}{*}{$\begin{array}{l}\text { Direct mentorship by postgraduate and indirect mentorship } \\
\text { by faculty (i.e., open triad, triad 7) }\end{array}$} & Three semesters & Female & White & 2 \\
\hline & Two semesters & Female & White & 1 \\
\hline \multirow[t]{2}{*}{ Faculty-only mentoring (triad 6) } & Three semesters & Female & Black or African American & 1 \\
\hline & Two semesters & Female & White & 1 \\
\hline \multirow[t]{2}{*}{ Postgraduate-only mentoring (triad 4) } & Two semesters & Male & Multiracial & 1 \\
\hline & One semester & Male & Hispanic or Latino & 1 \\
\hline
\end{tabular}


TABLE 2. Category definitions of the domains of support

\begin{tabular}{lr}
\hline Domains of support & Definition \\
\hline Intellectual support & $\begin{array}{r}\text { Described the mentor(s) teaching them about research/project, including the background information and its } \\
\text { procedures; introducing the tools, equipment, and technology }\end{array}$ \\
Professional support & $\begin{array}{r}\text { Described the mentor(s) providing advice on academic and career planning; values, standards, and practices of } \\
\text { the discipline; providing the big picture of the concepts, theories, and the language of the discipline; guiding } \\
\text { students toward greater responsibility and independence }\end{array}$ \\
Socioemotional support & Described the mentor(s) being accessible, helpful, patient, understanding, and respectful
\end{tabular}

studies (Chemers et al., 2011; Thiry and Laursen, 2011; Robnett et al., 2018). The definitions of the domains of support are given in Table 2 .

Overall, 23 of the 24 participants indicated that they had received intellectual support, whereas 19 participants reported receiving professional support, and 17 participants mentioned receiving personal/emotional support from their mentors throughout their research experiences. These three domains of support were used to explain students' perceived interactions and support provided by their mentors during their research experiences.

\section{Intellectual Support Regarding the Project}

According to the analyses, the subcategories of intellectual support were 1) introducing the basic terminology, equipment, and tools used in the laboratory; 2) describing subject-specific skills, techniques, and methods; and 3) explaining the project(s) and its procedures. The vast majority of the support participants commented on was related to knowledge of terminology and the use of types of equipment in the project, and a smaller number of comments were about support related to subject-specific skills, techniques, and methods regarding the procedures of the research project.

Participants indicated that senior members in the laboratory were crucial in helping them understand the concepts and procedures of the project along with promoting their scientific literacy. Participants also added that laboratory group meetings offered a fruitful context for them to experience how scientists communicate about their studies. One of the participants mentioned that, with the assistance of the senior members of the research group, she was able to better understand the project in the meetings:

In the group meetings, they are great. They talk about all their research. And I might not understand it all, but I do get the gist of it. And they break it down. They can talk amongst themselves and [with] all their different languages, and we would not understand, but they stop, and they break it down for us, so we do understand. So that is very helpful. It is very nice. They do not have to do that, but they do so we can understand.

Although 23 of the 24 participants indicated that they had received intellectual support during their research experiences, participants' comments about intellectual support showed differences regarding the mentoring structure and amount of research experience (see Figure 5). Participants who indicated receiving postgraduate-only mentorship (triad 4) expressed that the only support they received was intellectual support from postgraduates, regardless of their amount of research experience. The support they reported was help with increasing their understanding of the basic concepts related to the research project and the use of the equipment. Although both of the students who received postgraduate-only mentorship indicated they had received intellectual support from postgraduates, one of them, who gained one semester of research experience, commented on the insufficiency of this support and stated,

I think they would mostly try to teach me things that I have never experienced. Given that it was a med chem lab, most of it was orgo [organic chemistry]. Things that, at that point, I was not even aware of. The support I got was being guided for a certain task at a certain point and then just being thrown random information that did not really make sense to me. Just went in one ear, went out the other.

Of the participants who reported receiving faculty-only mentorship (triad 6), only one, who gained three semesters of research experience, indicated receiving intellectual support from faculty (see Figure 5), which was guidance to increase understanding of the research project and its procedures. Participants who indicated receiving open-triad (triad 7) and closed-triad (triad 8) mentorship commented on receiving intellectual support predominantly from postgraduates. These participants specified receiving support from postgraduates about basic scientific concepts and the use of tools and receiving support from faculty about research-related specific content knowledge. One of the participants explained this as follows:

If it is big, conceptual things, like about my project specifically, then I would go to Dr. K. [faculty mentor]. If it is something like I do not know how to do something or I need a refresher on something, then I would go to the PhD student.

One of the participants who reported receiving closed-triad mentorship (triad 8) and who gained one semester of research experience indicated that her primary mentor was a postgraduate and that she received only intellectual support only from her about the use of the tools and equipment in the laboratory.

\section{Professional Support to Undergraduate Researchers}

The subcategories on professional support include 1) academic and career advising, 2) modeling and guidance on scientific ethos, and 3) professional socialization. Participants' comments about academic and career advising indicated that they received support in the form of help choosing which classes to take, presentation of different career options, and guidance on how to determine the career paths they would like to pursue. One of 
the participants expressed that her mentor provided academic and career advice throughout her research experience:

I was pleasantly surprised by my professor mentoring me. I did not anticipate her being as involved in my schooling as she was. She gave me guidance in the lab but also offered advice on how I want to proceed in my undergraduate career. She has advised me on course scheduling and how to approach certain classes. She also gave me advice and guidance on what I plan to pursue post-graduation. With her guidance, I have decided to pursue a graduate degree and pursue a career in research instead of remaining pre-med and pursuing a medical career.

Some of the participants indicated that professional support promoted their engagement with the discipline and increased their understanding of the scientific community of practice. One of the participants mentioned that his mentor helped him see the connection of their research with the real world, which helped increase his understanding of the discipline:

My mentor makes them [the content] clear so they are not specific to our project. She tries to relate how our project and things that we are working on are impactful in all the STEM community and how we can sort of see the bigger picture of why we do this and why it is important. And so, I have learned a lot of stuff within my project, but the most changes have been related to the whole part about encompassing why we do what we do.

Professional socialization may promote students' authentic learning experience within a community of practice. Although this subcategory was mentioned with the least frequency compared with other subcategories of professional support, the par- ticipants indicated that this type of interaction helped them socialize in the scientific community. One of the participants stated,

Something that I really like in the ecology lab is the lab meeting because our lab meeting for our lab is with other labs as well. So, I have gotten to meet some people like other mentors. They will come in at our lab meeting, and some of their grad students will be there. And it is really interesting to have, I guess, that interaction with other labs as well so you are not as secluded. I think that is a really important aspect of the research experience is interacting with those that you are working [with].

Regarding the mentoring structure, there were also differences in the professional support that participants indicated that they had received from faculty or postgraduate mentors (see Figure 6). Participants who reported receiving postgraduate-only mentorship (triad 4) stated that they did not receive professional support during their research experiences, regardless of the amount of research experience. One of the participants, who also indicated that the intellectual support provided to him was insufficient and who mentioned his feelings of incompetence at the end of his first semester, stated, "I have not really talked about my career with them. However, I have not really asked for it." It may be crucial to communicate the needs and expectations of students and mentors at the beginning of the research experience.

Of the participants who indicated that they had received faculty-only mentorship (triad 6), only one reported receiving professional support from her mentor (see Figure 6). She mentioned receiving little guidance on the standards and practices of the biochemistry discipline. Participants who had open-triad

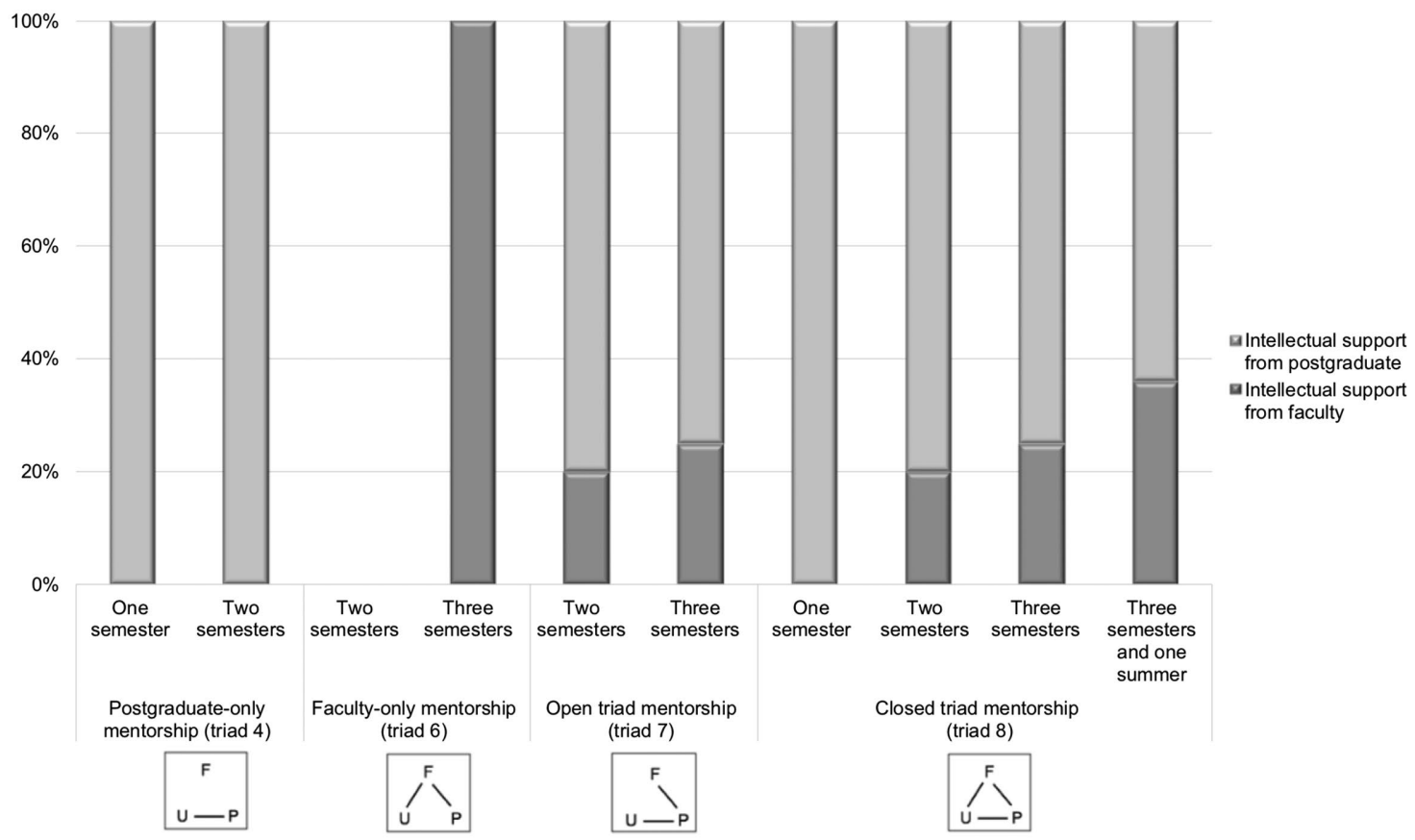

FIGURE 5. Percentages of perceived intellectual support from faculty and postgraduate mentors. 


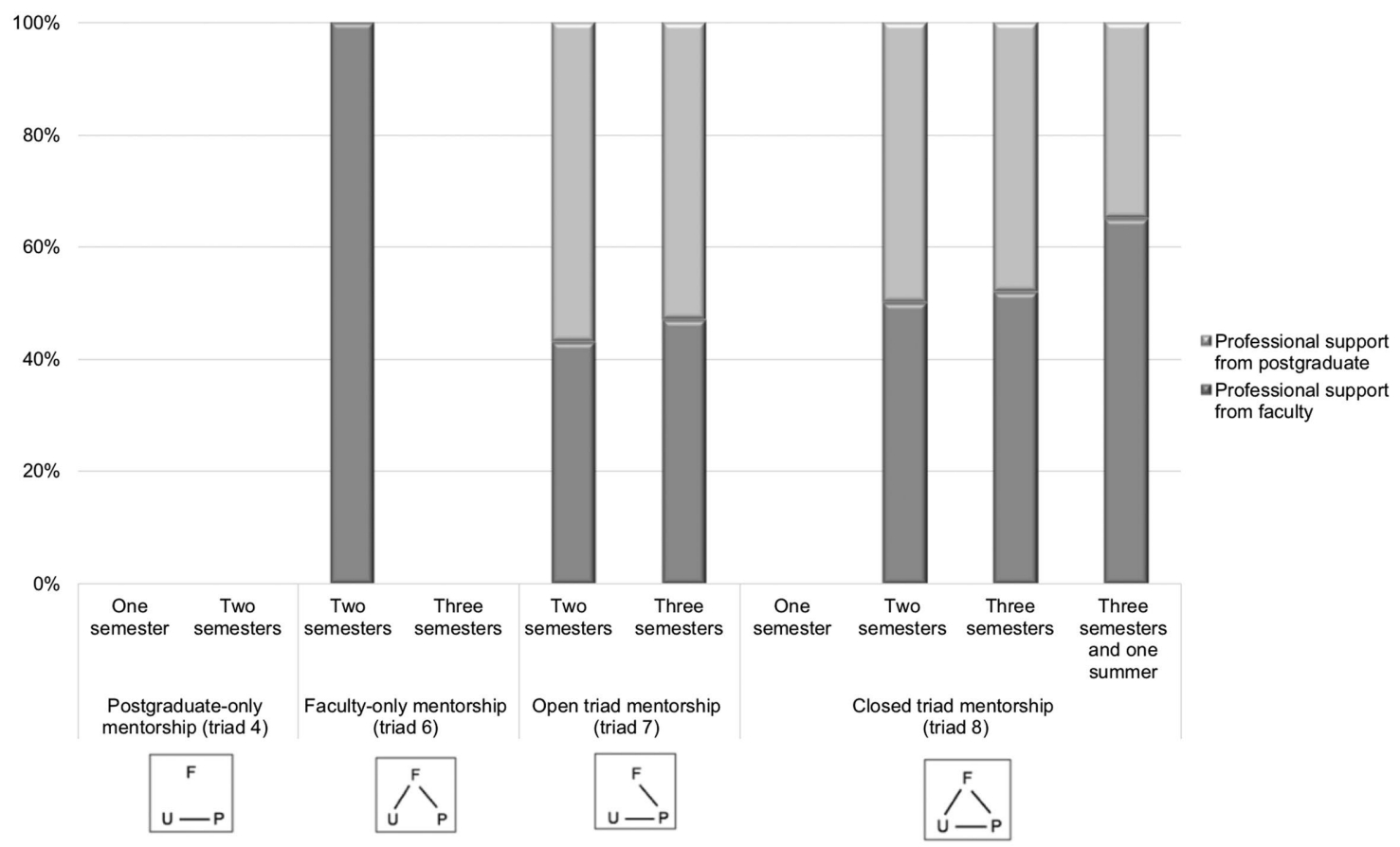

FIGURE 6. Percentages of perceived professional support from faculty and postgraduate mentors.

mentorship (triad 7) commented that they received professional support from postgraduates slightly more than from their faculty mentors (see Figure 6). These participants described receiving academic support from postgraduates in terms of which classes to take, when to take classes, and who to ask for help in planning their academic schedules.

Participants who reported having closed-triad mentorship (triad 8), the majority of whom gained more than three semesters of research experience, commented on receiving professional support mostly from faculty (see Figure 6). Their comments mainly noted receiving long-term academic and career advice from faculty, such as advice about career options after finishing their undergraduate degrees or tips about research-related careers. They also commented on their faculty mentors' support in professional socialization, especially during lab meetings, that helped them interact with other faculty professors and postgraduates. One of the participants in this group indicated receiving support from both faculty and postgraduates related to her socialization in the professional community and stated, "Like [for] their conferences, they would always tell me who they met, who they talked to, what it was about ... Or even if someone came into the lab to talk, [they] always introduced me, always included me in everything." As seen in Figure 6, participants who indicated receiving open-triad (triad 7) or closedtriad (triad 8) mentorship and who had two or more semesters of research experience reported receiving professional support.

\section{Personal/Emotional Support}

In participants' comments about personal/emotional support, they described their mentors as being accessible, helpful, patient, understanding, and respectful. One of the participants indicated that "Dr. S. was the best and most ideal mentor I could ask for. She was always understanding and patient throughout my journey. Most importantly, she was always there for me when I needed any sort of help or advice." Another participant explained the personal/emotional support she received from postgraduates and how this interaction made her consider potential academic careers:

My lab team makes me feel extremely welcome, and I regularly swing by the lab to study and get work done. The environment of the lab is extremely friendly but also very beneficial. I look up to all of the graduate students who work in the lab and learn from each of them. Graduate students are a good example of what pursuing a $\mathrm{PhD}$ would look like. Working in the lab has opened up my mind to potentially applying to $\mathrm{MD} / \mathrm{PhD}$ programs after graduation. I would have not seen this as a possibility had I not been exposed to graduate students, who have taught me about the demands of becoming a $\mathrm{PhD}$ candidate.

Similar to participants' comments related to the other mentoring support dimensions, participants' comments about personal/emotional support revealed differences regarding the mentoring structure and the amount of research experience (see Figure 7). Participants who received postgraduate-only (triad 4) or faculty-only (triad 6) mentorship, regardless of the amount of research experience, indicated that they did not receive personal/emotional support during their research experiences. At the end of first year, two of the participants expressed a lack of social, personal, and emotional support and complained about the unavailability of their mentors. One of them noted that "if professors were more available to talk about their research, it would be awesome."

Participants who indicated receiving open-triad (triad 7) or closed-triad (triad 8) mentorship and who gained two semesters or fewer of research experience did not indicate 


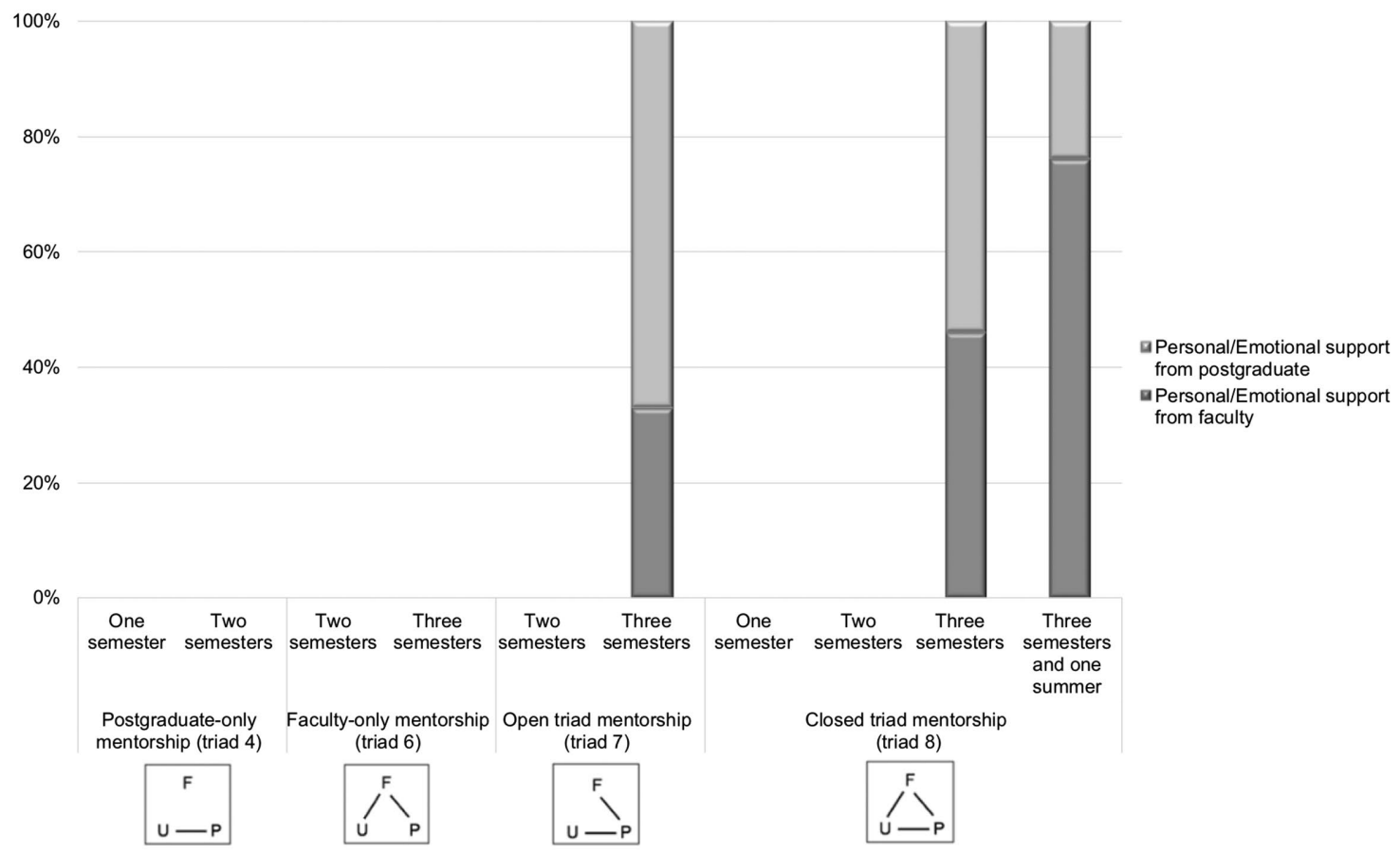

FIGURE 7. Percentages of perceived personal/emotional support from faculty and postgraduate mentors.

receiving personal/emotional support from their mentors (see Figure 7). Participants who indicated receiving opentriad mentorship (triad 7) and who gained three semesters of research experience reported receiving personal/emotional support mostly from their postgraduates and commented on how accessible, patient, and friendly their postgraduate mentors were. Participants who indicated receiving closed-triad mentorship (triad 8) and who gained three semesters or more of research experience reported receiving personal/ emotional support mainly from faculty mentors (see Figure 7). One of the participants indicated that it was scary to reach out to his mentors during the first semester of his research experience:

I think that the mentors should have a closer relationship with the scholar in my experience. My mentor is there, but it is scary talking to them at the time because I believe that they expect me to know more than I actually do.

However, in his second interview, this participant expressed a positive change in his relationship with his mentor during his sophomore year research experience:

It was completely different. When they are making lab meetings, they try to incorporate my schedule into that meeting as well to make sure I am able to attend. I was able to lead a lab meeting this year, kind of see what information that I might be miscommunicating, make sure that I understand fully what is going on. I have had a lot more meetings with my mentor, not necessarily just about the research but about my overall time here, how I am doing in my classes. Academically, what is it that I want to do for my future. Therefore, he has played more of a mentor role than a research PI. So definitely a huge difference.

\section{Summary of the Findings Regarding the Perceived Domains of Support}

Participants who received postgraduate-only mentorship (triad 4) indicated receiving only intellectual support. Participants who received faculty-only mentorship (triad 6) expressed receiving intellectual or professional support during their research experiences. On the other hand, participants who indicated receiving open-triad (triad 7) or closed-triad (triad 8) mentorship and who gained three semesters or more of research experience mentioned that they had received all three types of support, whereas participants in these groups who gained two semesters of research experience mentioned receiving intellectual and professional support (see Figure 8). Therefore, according to the analysis in this study, when participants were provided with open-triad (triad 7) or closed-triad (triad 8) mentorship and when the participants gained three semesters or more of research experience, they reported receiving all three types of support.

Participants who indicated receiving postgraduate-only mentorship (triad 4) mentioned receiving only intellectual support from postgraduates. Participants who indicated receiving faculty-only mentorship (triad 6) reported receiving either intellectual or professional support from faculty. Participants who indicated that they received open-triad (triad 7) or closedtriad (triad 8) mentorship reported that the most common form of support they received from faculty was professional support and that the most common form of support from postgraduates was intellectual support (see Table 3).

Participants who indicated they had received closed-triad mentorship (triad 8) had almost equal numbers of coding references for the total support provided by both faculty and postgraduates. Their comments included more references to 


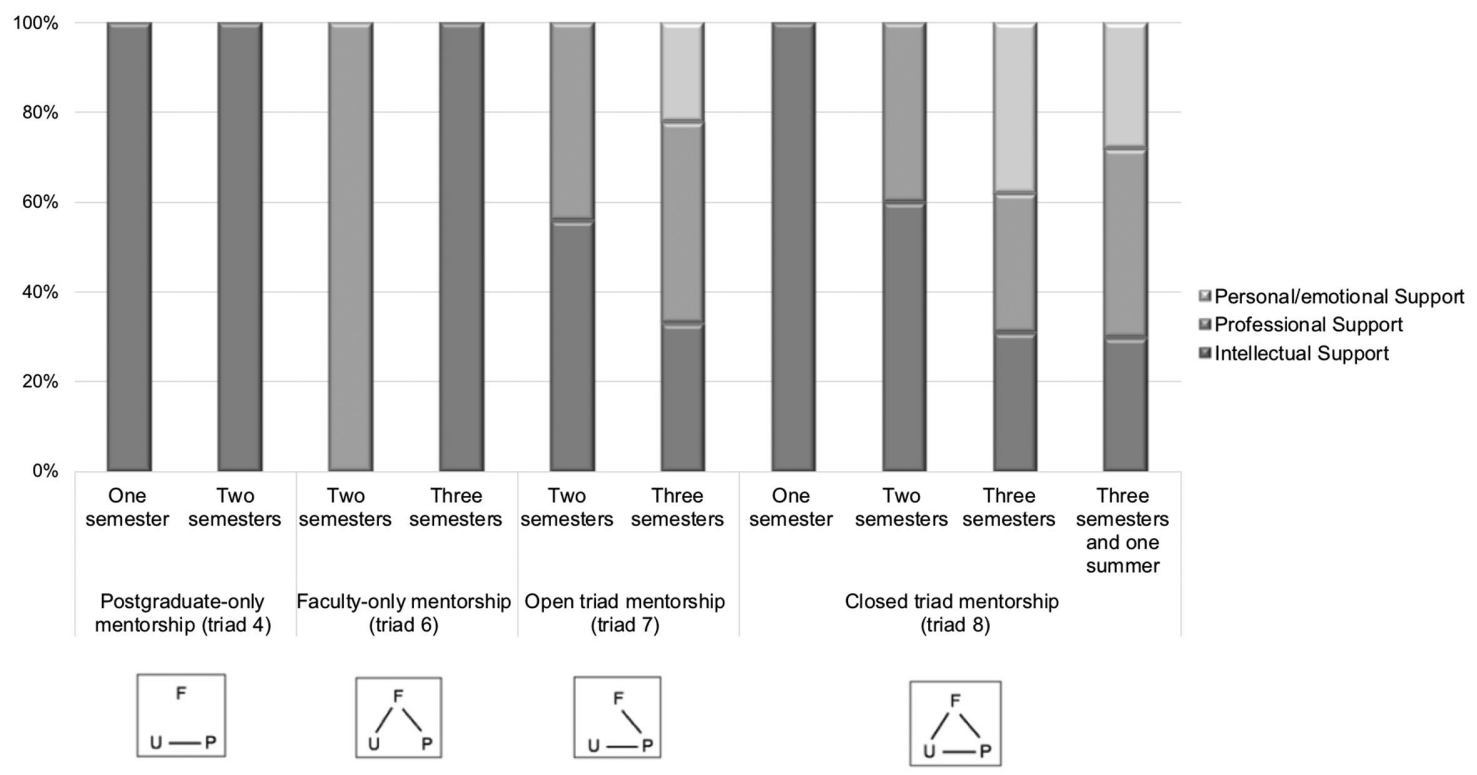

FIGURE 8. Perceived domains of support regarding the mentoring structures and the amount of research experience gained.

professional and personal/emotional support from faculty and more references to intellectual support from postgraduates. Participants who indicated that they had received open-triad mentorship (triad 7) reported receiving intellectual support predominantly from postgraduates. Compared with the comments of participants who indicated they received closed-triad mentorship (triad 8), their comments included a similar number of references to professional support from faculty and postgraduates but many fewer references to personal/emotional support.

\section{DISCUSSION}

Prior research on mentoring structures revealed that undergraduate researchers in different mentoring triads reported different outcomes (Aikens et al., 2016). In particular, participants who received closed-triad mentorship (triad 8) reported more positive outcomes than participants with other mentoring structures (Aikens et al., 2016). The findings of this study indicate differences in the perceived domains of support described by early-year undergraduate researchers in their interviews and progress reports. These differences illustrate various support mechanisms depending on the mentoring structure and the amount of research experience students gained, which reveals several implications and recommendations for UR program developers and researchers. A better understanding of undergraduate researchers' support networks can help better communicate the needs of undergraduate researchers in different mentoring triads and find ways to improve the outcomes of UR experience (Bradley et al., 2017). Therefore, it is crucial to investigate mentoring interactions and the types of support provided to undergraduate researchers during their UR experiences.

Participants who indicated that they had received faculty-only mentorship (triad 6) reported receiving intellectual or professional support from faculty. Faculty professors are key actors in the mentoring structure, and prior research has shown positive outcomes of direct interaction with faculty for undergraduate researchers (Dolan and Johnson, 2010; Joshi et al., 2019). In particular, early-year undergraduates who are also new to the field benefit greatly from direct student-faculty interaction within the research context (Fuentes et al., 2014). However, training undergraduates, particularly early-year undergraduates who lack the basic skills and knowledge of the discipline, and providing high-quality mentorship requires additional time and effort. Faculty professors' support, by itself, may not be enough to provide the necessary guidance and assistance to engage undergraduates in a community of practice. UR programs should be designed to provide direct interactions with faculty mentors as well as postgraduates to increase the support provided by both members of the mentoring triad, which may play a role in undergraduate researchers' engagement with and commitment to research.

Although the majority of the participants indicated that postgraduates were their primary mentors, most of them also reported having direct or indirect interaction with a faculty mentor in the laboratory. Participants who indicated receiving open-triad (triad 7) or closed-triad (triad 8) mentorship and who gained three semesters or more of research experience reported receiving all three types of support. Participants who received open-triad mentorship (triad 7) commented that they received more support from postgraduates than faculty, whereas participants who received closed-triad mentorship (triad 8) reported receiving equal support from faculty and postgraduates; in addition, regarding the type of support provided to them, participants with both types of mentorship received more professional and personal/emotional support from faculty and more intellectual support from postgraduates. Newcomers need various types and amounts of support within a community of practice (Wenger, 1998). The findings indicate that direct mentorship by faculty and postgraduates results in the distribution of roles in the mentoring structure. Consistent with the literature, the findings suggest that such direct mentorship may contribute to improved research outcomes (Aikens et al., 2016; 
TABLE 3. Frequencies of the coding references regarding the domains of support provided to the participants from faculty and postgraduate mentors

\begin{tabular}{|c|c|c|c|c|c|c|}
\hline \multirow[b]{2}{*}{ Mentoring structure } & \multicolumn{3}{|c|}{ Support from faculty } & \multicolumn{3}{|c|}{ Support from postgraduates } \\
\hline & $\begin{array}{r}\text { Intellectual } \\
\text { support (\%) }\end{array}$ & $\begin{array}{l}\text { Professional } \\
\text { support (\%) }\end{array}$ & $\begin{array}{c}\text { Personal/ } \\
\text { emotional } \\
\text { support (\%) }\end{array}$ & $\begin{array}{r}\text { Intellectual } \\
\text { support (\%) }\end{array}$ & $\begin{array}{l}\text { Professional } \\
\text { support (\%) }\end{array}$ & $\begin{array}{c}\text { Personal/ } \\
\text { emotional } \\
\text { support (\%) }\end{array}$ \\
\hline Postgraduate-only mentorship (triad 4) & 0 & 0 & 0 & 100 & 0 & 0 \\
\hline Faculty-only mentorship (triad 6) & 50 & 50 & 0 & 0 & 0 & 0 \\
\hline Open-triad mentorship (triad 7) & 9 & 22 & 4 & 30 & 26 & 9 \\
\hline Closed-triad mentorship (triad 8) & 7 & 25 & 19 & 20 & 17 & 12 \\
\hline
\end{tabular}

Joshi et al., 2019). Given the potential benefits to undergraduate researchers, UR programs should be designed to provide clear roles, responsibilities, and expectations from mentors to maximize the support provided to students.

As the participants in this study gained their research experience in their first and sophomore years, their content knowledge about the field, subject-specific knowledge about the discipline, and skills were limited, which influenced their understanding of the projects and procedures. Early-year undergraduate researchers may need more intellectual support than their junior and senior peers in a community of practice. Moreover, postgraduates, who are also mentored by faculty, may have limited mentoring abilities (Dolan and Johnson, 2010; Limeri et al., 2019). As Aikens et al. (2016) stated, "Postgraduates are not able to fully broker the resources that faculty can offer" (p. 12). Therefore, postgraduate-only mentorship (triad 4) may involve a higher risk for insufficient mentoring and may result in undergraduates being discouraged from pursuing research-related career paths (Dolan and Johnson, 2010). The analysis in this study revealed that participants who indicated that they received postgraduate-only mentorship (triad 4) reported receiving only intellectual support from their postgraduate mentors, regardless of the amount of research experience they gained. One of the participants in this group reported the insufficiency of the support provided to him but also indicated that "he did not ask for it." Therefore, the findings of this study suggest that postgraduates need to be provided with opportunities to improve their mentoring skills. Moreover, UR programs should be designed to communicate student and mentor expectations, along with clearly defined roles and responsibilities, to increase their efficiency.

The findings also indicate that participants with open-triad (triad 7) and closed-triad (triad 8) mentorships mentioned receiving personal/emotional support when they participated in three semesters or more of research of experience. Participants who received closed-triad mentorship (triad 8) commented on receiving personal/emotional support more than participants who received open-triad mentorship (triad 7), and their comments noted receiving personal/emotional support mostly from faculty. Students have been found to be at a higher risk of leaving the field or to be less inclined to choose a research-related career when they are not socially or intellectually integrated into a community of practice (Thiry et al., 2012). We suggest that mentors should start providing social, personal, and emotional support early in undergraduate researchers' research experiences to increase students' engagement and their commitment to scientific practice (Robnett et al., 2018).

\section{LIMITATIONS OF THE STUDY AND FUTURE WORK}

The investigation of the SUSTAIN project participants' research experience provides an in-depth understanding of the mentoring structures and types of support provided to them in the context of a large, research-intensive, private university in the northeastern United States during the time of this study. However, this study has several limitations. First, sample selection is a limitation of the study. The participants for this study were the participants of the SUSTAIN project, a select group of high-achieving, low-income undergraduate STEM students in the biology and chemistry departments at one private research university. The participating students not only were mentored but also were part of a full-fledged program that included community-building activities, peer-led team learning, and living-learning experiences, which may further limit the generalizability of these findings. There may be differences in the mentoring structures and types of support provided to different student groups and at different types of institutions, but this study cannot predict those differences. Although the findings of this study are not generalizable, this study may provide insight into student groups under comparable conditions (Creswell and Poth, 2018).

Moreover, the participants in this study were predominantly female, first-generation, low-income college students from diverse backgrounds. The findings of this study are limited to reflecting the perspectives of this group of students' research experience in this context. Engle and Tinto (2008) reported that the dropout rate or rate of switching to a non-STEM major among first-generation and low-income students is four times higher than that among their non-first generation, non-low income peers. One main reason for this difference stated in the higher education literature is that "underrepresented students often have less exposure to STEM career options" (as cited in Hernandez et al., 2013, p. 21). Therefore, it is crucial to better explain the experiences of these students in STEM-related activities and to identify the "best practices" to keep them in STEM fields.

Another limitation is that this study includes only student perspectives and does not include the perspectives of faculty mentors or postgraduates, who are the two other important pieces of the triad mentoring structure. In this study, interviews and progress reports revealed detailed information about the perceived support provided to the SUSTAIN project participants and their experiences in research laboratories. Given the potential benefit of high-quality multiyear research experiences for students, future research is necessary to explore faculty and postgraduate mentors' perspectives about mentoring structures; the types of support provided to undergraduate 
researchers; and both undergraduate researchers' and their mentors' challenges, needs, and concerns (Joshi et al., 2019).

Finally, participant observation throughout their research experience was not used to triangulate the interview responses and progress reports. Interviews at the end of each year and progress reports over time provided in-depth exploration (Creswell, 1998). As an alternative, further research may include participant observation to explore the actual experiences of all three actors within mentoring triads. Furthermore, this study focused on how participants described the types of support they received in three domains: intellectual, professional, and personal/emotional support. Future research should investigate the amount, quality, and impact of support to undergraduate researchers related to development of identity as a scientist.

\section{CONCLUSION}

This study investigated student experiences, illustrated the possible relationships of mentoring and the type of support provided to undergraduate researchers, and identified the most promising avenues for future studies. In this study, the vast majority of the participants who received closed-triad mentorship (triad 8) gained three semesters or more of research experience, while less than half of the participants who reported receiving open-triad (triad 7), faculty-only (triad 6) or postgraduate-only (triad 4) mentorship gained three semesters of research experience. The different amounts of research experience among participants may indicate their interest and commitment to the field in general or to a research-related career in particular (Thiry et al., 2012). Although most UR programs are designed to provide single, short-term research opportunities for students to increase the number of undergraduates who can benefit from this experience (e.g., Research Experiences for Undergraduates programs funded by the NSF), the findings of this study support the literature on the benefits of multiyear research experiences with effective multi-mentor support (Thiry et al., 2012).

\section{ACKNOWLEDGMENTS}

This study would not have been possible without the SUSTAIN Scholars who participated in the project and shared their stories. Their honesty and willingness to reflect on their personal experiences were greatly appreciated. We also thank two anonymous reviewers and monitoring editor Dr. Derek Braun for thoughtful feedback on the earlier versions of this article. The material presented here is based upon work supported by the NSF under grant no. 1644148. Any opinions, findings, and conclusions or recommendations expressed in these materials are those of the authors and do not necessarily reflect the views of the NSF.

\section{REFERENCES}

Aikens, M. L., Robertson, M. M., Sadselia, S., Watkins, K., Evans, M., Runyon C. R., ... \& Dolan, E. L. (2017). Race and gender differences in undergraduate research mentoring structures and research outcomes. CBE-Life Sciences Education, 16(2), ar34. https://doi.org/10.1187/cbe.16-07-0211

Aikens, M. L., Sadselia, S., Watkins, K., Evans, M., Eby, L. T., \& Dolan, E. L. (2016). A social capital perspective on the mentoring of undergraduate life science researchers: An empirical study of undergraduate-postgraduate-faculty triads. CBE-Life Sciences Education, 15(2), ar16. https:// doi.org/10.1187/cbe.15-10-0208

Amaya, L. R., Betancourt, T., Collins, K. H., Hinojosa, O., \& Corona, C. (2018). Undergraduate research experiences: Mentoring, awareness, and perceptions - a case study at a Hispanic-serving institution. International Journal of STEM Education, 5(1), 9. https://doi.org/10.1186/s40594-018 -0105-8

Bowman, N. A., \& Holmes, J. M. (2018). Getting off to a good start? First-year undergraduate research experiences and student outcomes. Higher Education, 76(1), 17-33. https://doi.org/10.1007/s10734-017-0191-4

BrackaLorenz, A., Garvey, J. C., Hurtado, S. S., \& Latopolski, K. (2017). High-impact practices and student-faculty interactions for gender-variant students. Journal of Diversity in Higher Education, 10(4), 350-365. https://doi.org/10.1037/dhe0000065

Bradley, E. D., Bata, M., Gibbon, H. M. F., Ketcham, C. J., Nicholson, B. A., Pollock, M., \& Dolan, E. (2017). The structure of mentoring in undergraduate research: Multi-mentor models. Scholarship and Practice of Undergraduate Research, 1(2), 35-42. https://doi.org/10.18833/spur/1/2/12

Chemers, M. M., Zurbriggen, E. L., Syed, M., Goza, B. K., \& Bearman, S. (2011). The role of efficacy and identity in science career commitment among underrepresented minority students. Journal of Social Issues, 67(3) 469-491. https://doi.org/10.1111/j.1540-4560.2011.01710.x.

Creswell, J. W. (1998). Qualitative inquiry and research design: Choosing among five traditions. Thousand Oaks, CA: Sage.

Creswell, J. W., \& Poth, C. N. (2018). Qualitative inquiry and research design Choosing among five approaches. Sage.

Dolan, E., \& Johnson, D. (2009). Toward a holistic view of undergraduate research experiences: An exploratory study of impact on graduate/postdoctoral mentors. Journal of Science Education and Technology, 18(6), 487. https://doi.org/10.1007/s10956-009-9165-3

Dolan, E. L., \& Johnson, D. (2010). The undergraduate-postgraduate-faculty triad: Unique functions and tensions associated with undergraduate research experiences at research universities. CBE-Life Sciences Education, 9(4), 543-553. https://doi.org/10.1187/cbe.10-03-0052

Engle, J., \& Tinto, V. (2008). Moving beyond access: College success for low-income, firstgeneration students. The Pell Institute for the Study of Opportunity in Higher Education. Washington, DC: Author.

Feng, X., \& Behar-Horenstein, L. (2019). Maximizing Nvivo utilities to analyze open-ended responses. Qualitative Report, 24(3), 563-571. Retrieved March 17, 2019, from https://nsuworks.nova.edu/tqr/vol24/iss3/11

Fuentes, M. V., Alvarado, A. R., Berdan, J., \& DeAngelo, L. (2014). Mentorship matters: Does early faculty contact lead to quality faculty interaction? Research in Higher Education, 55(3), 288-307. https://doi.org/10.1007/ s11162-013-9307-6

Garvey, J. C., BrckaLorenz, A., Latopolski, K., \& Hurtado, S. S. (2018). High-impact practices and student-faculty interactions for students across sexual orientations. Journal of College Student Development, 59(2), 210 226. https://doi.org/10.1353/csd.2018.0018

Gregerman, S. R., Lerner, J. S., Von Hippel, W., Jonides, J., \& Nagda, B. A. (1998). Undergraduate student-faculty research partnerships affect student retention. Review of Higher Education, 22(1), 55-72. https://doi .org/10.1353/rhe.1998.0016

Hernandez, P. R., Schultz, P., Estrada, M., Woodcock, A., \& Chance, R. C. (2013). Sustaining optimal motivation: A longitudinal analysis of interventions to broaden participation of underrepresented students in STEM. Journal of Educational Psychology, 105(1), 89.

Hmelo, C. E., \& Evensen, D. H. (2000). Problem-based learning: Gaining insights on learning interactions through multiple methods of inquiry. Problem-based Learning: A Research Perspective on Learning Interactions, 1(1), 1-16.

Hunter, A. B., Laursen, S. L., \& Seymour, E. (2007). Becoming a scientist: The role of undergraduate research in students' cognitive, personal, and professional development. Science Education, 91(1), 36-74. https:// doi.org/10.1002/sce.20173

Johnson, W. B. (2015). On being a mentor: A guide for higher education faculty. New York: Routledge.

Joshi, M., Aikens, M. L., \& Dolan, E. L. (2019). Direct ties to a faculty mentor related to positive outcomes for undergraduate researchers. BioScience, 69(5), 389-397. https://doi.org/10.1093/biosci/biz039

Kim, Y. K., \& Sax, L. J. (2009). Student-faculty interaction in research universities: Differences by student gender, race, social class, and first-generation status. Research in Higher Education, 50, 437-459. https://doi .org/10.1007/s11162-009-9127-x 
Kuh, G. (2008). High-impact educational practices: What they are, who has access to them, and why they matter (pp. 19-34). Washington, DC Association of American Colleges and Universities.

Lave, J., \& Wenger, E. (1991). Situated learning: Legitimate peripheral participation. New York: Cambridge University Press.

Leech, N. L., \& Onwuegbuzie, A. J. (2011). Beyond constant comparison qualitative data analysis: Using NVivo. School Psychology Quarterly, 26(1), 70. https://doi.org/10.1037/a0022711

Limeri, L. B., Asif, M. Z., \& Dolan, E. L. (2019). Volunteered or voluntold? The motivations and perceived outcomes of graduate and postdoctoral mentors of undergraduate researchers. CBE-Life Sciences Education, 18(2), ar13. https://doi.org/10.1187/cbe.18-10-0219

Linn, M. C., Palmer, E., Baranger, A., Gerard, E., \& Stone, E. (2015). Undergraduate research experiences: Impacts and opportunities. Science, 347(6222), 1261757. https://doi.org/10.1126/science.1261757

Lopatto, D. (2010). Undergraduate research as a high-impact student experience. Peer Review, 12(2), 27.

Merkel, C. A. (2003). Undergraduate research at the research universities New Directions for Teaching and Learning, 2003(93), 39-54.

Morales, D. X., Grineski, S. E., \& Collins, T. W. (2018). Effects of gender concordance in mentoring relationships on summer research experience outcomes for undergraduate students. Science Education, 102(5), 1029 1050. https://doi.org/10.1002/sce.21455

Pollock, M., Ketcham, C. J., Gibbon, H. M. F., Bradley, E. D., \& Bata, M. (2017). Beyond the mentor-mentee model: A case for multi-mentoring in undergraduate research. Perspectives on Undergraduate Research and Mentoring, 6, 1-14.

Robnett, R. D., Chemers, M. M., \& Zurbriggen, E. L. (2015). Longitudinal associations among undergraduates' research experience, self-efficacy, and identity. Journal of Research in Science Teaching, 52(6), 847-867. https://doi.org/10.1002/tea.21221

Robnett, R. D., Nelson, P. A., Zurbriggen, E. L., Crosby, F. J., \& Chemers, M. M. (2018). Research mentoring and scientist identity: Insights from undergraduates and their mentors. International Journal of STEM Education, 5(41), 1-14. https://doi.org/10.1186/s40594-018-0139-y
Rodenbusch, S., Hernandez, P. R., Simmons, S. L., \& Dolan, E. L. (2016). Early engagement in course-based research increases graduation rates and completion of science, engineering, and mathematics degrees. CBE-Life Sciences Education, 15(1), 1-10. https://doi.org/10.1187/cbe.16-03-0117

Schreiner, L. A., \& Tobolowsky, B. F. (2018). The role of faculty in sophomore success. New Directions for Higher Education, 183, 59-70. https://doi org/10.1002/he.20293

Schwartz, J. (2012). Faculty as undergraduate research mentors for students of color: Taking into account the costs. Science Education, 96(3), 527542. https://doi.org/10.1002/sce.21004

Spradley, J. P. (1980). Participant observation. New York: Holt, Rinehart, and Winston.

Syed, M., Zurbriggen, E. L., Chemers, M. M., Goza, B. K., Bearman, S., Crosby, F. J., ... \& Morgan, E. M. (2018). The role of self-efficacy and identity in mediating the effects of STEM support experiences. Analyses of Social Issues and Public Policy, 19(1), 7-49. https://doi.org/10.1111/asap.12170

Thiry, H., \& Laursen, S. L. (2011). The role of student-advisor interactions in apprenticing undergraduate researchers into a scientific community of practice. Journal of Science Education and Technology, 20(6), 771-784. https://doi.org/10.1007/s10956-010-9271-2

Thiry, H., Laursen, S. L., \& Hunter, A. B. (2011). What experiences help students become scientists? A comparative study of research and other sources of personal and professional gains for STEM undergraduates. Journal of Higher Education, 82(4), 357-388. https://doi.org/10.1080/0 0221546.2011.11777209

Thiry, H., Weston, T. J., Laursen, S. L., \& Hunter, A. B. (2012). The benefits of multi-year research experiences: Differences in novice and experienced students' reported gains from undergraduate research. CBE-Life Sciences Education, 11(3), 260-272. https://doi.org/10.1187/cbe.11-110098

Tinto, V. (2008). Research and practice of student retention: What next? Journal of College Student Retention: Research, Theory \& Practice, 8(1), 1-19. https://doi.org/10.2190/4YNU-4TMB-22DJ-AN4W

Wenger, E. (1998). Communities of practice: Learning as a social system. Systems Thinker, 9(5), 2-3. https://doi.org/10.1177/135050840072002 